\title{
Designing for People, Not for Man: The Recurring Role of Social Science in Architectural Discourse and Practice
}

\author{
JULIA GRINKRUG \\ Academy of Art University, California College of the Arts
}

\author{
HANS SAGAN \\ Academy of Arts University
}

\begin{abstract}
This paper focuses on the recurring role of social science in architectural discourse, education, and practice, offering a review of how architectural theory has cyclically sought out other ways of approaching issues of space, place, and being, and has, in the process, transformed and strengthened the field. The paper suggests that, perhaps, we are entering a new outreach phase, wherein the discipline is again looking beyond its boundaries to find useful ways of thinking and engaging with the real world.
\end{abstract}

Most of us would agree that we live in "times of political and polemical uncertainty," as suggested in the call for papers. However, despite "a tendency to secure one's keep and fortify one's borders," there is an apparent openness in the architectural field today towards new intersections. As the call for papers outlines, until recently it has seemed like Architecture has forgotten how to engage with real interdisciplinarity, instead turning inward and becoming increasingly self-referential. However, this has not always been the case. Architecture theorists have cyclically sought out other ways of approaching issues of space, place, and being, and have in the process transformed and strengthened the field. This cycle of interdisciplinary engagement has distinct phases: insularity, crisis, introspection, outreach, and integration. The tone of the call indicates that perhaps we are entering the outreach phase, wherein the discipline looks again beyond its boundaries to try and find useful ways of thinking and engaging with the real world. Indeed, there is ample evidence for this direction in current architectural trends ${ }^{1}$ as it will be demonstrated below.

This paper focuses on the recurring role of social science in architectural discourse, which represents the innate premise of architecture as a social and cultural practice. The history of interdisciplinary exchange provides a wealth of insightful precedents that can shed light towards current developments. Among these are methodologies that were specifically developed to combine the needs and the skill sets from both fields, such as behavioral analysis, naturalistic observations and 'sense of place' surveys. The authors of this paper, being architectural educators, are interested in analyzing these historical moments, unpacking both the sociopolitical context that enabled them, and the legacy they have left within the profession. Recognizing the rising opportunity for the renewed outreach, there is a pressing need for a critical assessment of the premises and pitfalls in such interaction.
Is Architecture capable of true interdisciplinary exchange? What are the necessary components for such exchange and what are the barriers for its success? How can we leverage the lessons from previous iterations? A cardinal problem that critics raise again and again is rooted in the dual identity of the field of architecture, being situated between science and art. This ambivalence leads to an inherent contradiction within the field, breeding incongruence in methodologies and value systems. One example of such incongruence is related to the notion of innovation. In science, innovation derives from scientific research based in discovery and the unearthing of new knowledge. Being a visual art form that aspires to practicality, the architectural profession often replaces this kind of discovery with the invention of new types of formal representation. Instead of producing new forms of knowledge, architecture is obsessed with the production of new formal expressions, each striving toward novelty in function. How then should scientific research be introduced to architecture students?

\section{"NOW WHAT?!" [AGAIN] - THE RISE OF SOCIAL IMPERATIVE IN ARCHITECTURE TODAY.}

A current exhibition entitled Now What?! Advocacy, Activism \& Alliances in American Architecture since 1968, aspires to provide an "intersectional and interdisciplinary look ... [that] examines diversity and activism in the design professions," showcasing the history of "profession's participation in larger social and political movements" 2 . Now What?! signifies a growing interest among architects in socially oriented design. Savvy with exuberant form finding, and frustrated with market driven directives, architects nowadays seek to reclaim leading positions in spatial decision-making. As stated in the exhibition's agenda, "in recent years, there has been a new wave of initiatives and advocacy emerging in the US that draw attention to these critical issues."

The theme of last year's US Pavilion at the Venice Biennale (2018), entitled Dimensions of Citizenship, signalled a nation-wide acknowledgement of the civic bias in architecture, asking: "how might architecture respond to, shape, and express rhizomatic and paradoxical conditions of citizenship?" 3 If the US Pavilion is an indication of a national trend, the Pritzker Prize nominations reassert a worldwide paradigm. Recent Pritzker Prize laureates Alejandro Aravena (2016) and Shigeru Ban (2014) are model 'citizen architects', who center their practice 
on public-interest-design, design for the poor, disaster relief and advocacy planning. This agenda is radically different from the qualities valued in the work of previous nominees such as Peter Zumthor (2009) and Jean Nouvel (2008), who represent a striving for architecture's autonomy and advance explorations in form, materiality and performance.

The examples listed above indicate a shift in architectural discourse from an exclusive concentration on architectural masterpiece, dissociated from reality, towards the engagement in everyday practicality and real-life issues, which reaffirms architectural agency in socio-economic processes. Grassroots movements and experimental initiatives, such as WIMBY, Creative Place-making, Do It Yourself, Tactical Urbanism, Off The Grid, Pop-Up Villages and others, amass towards an all encompassing re-definition of architectural practice. Initiated at the turn of the millennium as radical, avant-garde experiments, these movements have already become commonplace and exemplary practices, being adopted and emulated by cities and corporations worldwide. Architectural colleges are also rushing to incorporate courses and programs that establish alliances with community partners, such as design-build, asset mapping, and community engagement.

Among the many incarnations of the social imperative in architecture, there is one common denominator - the need to understand cultural and behavioral patterns of the recipients of architectural product. Seeking to be more deeply involved in social processes, there is an increasing desire among architects to master ethnographic analytical tools as part of their professional repertoire. In this new intellectual climate, the questions posed by the call for paper, regarding the adequacy of research tools provided to architectural students, acquire new poignancy, considering the higher degrees of accountability, required for research that involves human subject.

As the popularity of public participation and socialinterest-design grows, there is a growing critique of its implementations ${ }^{4}$. This critique addresses the unintended consequences of architectural involvement, which has been too quick and too superficial in its attempt to respond to complex socio-political issues. As it happened in the past, these well-intended interventions, lacking in rigorous research and proper training, have often created adverse effects for their subjects. Readings of sociological or anthropological theory are mined not for rich data on the practicalities of suiting environment to behavior, but rather they are used as a sort of 'mood board' to add design gestures pointing toward social awareness. In short, architects have proceeded with designs intended to affect social behavior without a comprehensive understanding of how people actually behave. ${ }^{5}$
As the call for paper identifies, within the striving to "diversify the scope and culture of architectural practice" there is a need to produce students and professionals "equipped to conduct meaningful independent research." In order to identify the blind spots in such attempts, the following chapters offer a critical history of the constructive friction between architecture and social sciences during the 20th century, tracing its cyclical trajectory and unpacking the triggers, premises and processes of each cycle.

\section{PREVIOUS OUTREACH AND ITS DISSOLUTION}

Ever since the declaration of maxim 'Form Follows Function' by Louis Sullivan, the architectural discipline has been wrestling with the imbalanced dualism of its two basic attributes - form and function. By putting forth a decisive bias towards functionality, the modern movement rebelled against the previously established stability, which had been promoted by the traditional architectural education meticulously carried on into the 20th Century by the Ecole de Beaux Arts. Rooted in a long-lasting humanist tradition ${ }^{6}$ established by Vitruvius with his tripartite equilibrium formula of Commodity-Firmness-Delight, this traditional paradigm reflected an almost sacrosanct acknowledgement of the ultimate balance between the functional (i.e. rational, scientific and practical) and aesthetic (i.e. sensual, intuitive, artistic) principles of architecture. The rebellious spirit of the early 20th Century set this dialectic in motion and architectural discourse has been diametrically gravitating towards one or another extreme ever since, turning its skin several times during the last century.

Reyner Banham defined this irresoluble dialectic as "ethics vs. aesthetics" and Michael K. Hays, a generation later, introduced the antagonism between "history and autonomy" These critiques represent an inherent contra- diction within the profession. Architecture's desire to be relevant in the world and in the moment has been always fighting the fear of losing autonomy and self worth. Three distinct moments can be identified as the heydays of "ethical" (vis-à-vis Banham) or "historical" (vis-à-vis Hays) bias in architecture, when the desire to make a contribution outweighed the fear of dissolution. These moments can be associated with specific historical and political contexts that acted both as their triggers and as platforms for their enactment.

\section{THE FIRST CYCLE - PRE AND POST WAR MODERNITY}

The first wave was aligned with the aftermath of the Industrial Revolution. Alongside the uptake of industrial principles of machine processes and assembly lines, European architects such as Taut and projects like the Weissenhof- Siedlung developed and displayed architecture that was both novel in form and took into account social needs. ${ }^{9}$ Rapid industrialization and urbanization over the preceding century had produced a human and technological explosion leading to poor urban living conditions and housing. Many theorists 
and practitioners promoted the idea that architecture could be designed to satisfy social needs and solve social problems, and scaled up in an industrial fashion, taking advantage of developments in production to decrease costs. Combined with socialist politics and the deprivations of the Depression, the humanitarian crisis in the teens and 20s gave rise to the prevalence of social imperative in public and political debate in the 1930s. In the US, the premise of this social bias was highlighted by the establishment of Chicago School of Sociology that has played a significant role in the evolution of the discipline of urban planning. ${ }^{10}$

Furthermore, with the post-war increase in emphasis on technical rationality, architecture as a field began to integrate more kinds of technical knowledge into not only the mobilization of new materials and techniques but into the design process itself. 'Strategies of reflection' (Schön), efficiency, and systematicity were applied directly to how architects designed as well as how they approached design issues. This outreach eventually extended into sociology, psychology, and anthropology in the early and mid-1960s, as an outgrowth of the expectation that social planning through design was achievable and desirable. Edward W. Soja describes the postwar reciprocity between spatial and social fields as a 'spatial turn'11. (Hence the development of the sub fields, such as urban sociology, ethnography, vernacular studies).

Modernist recognition of experts fostered incorporation of established and proven methods to gather data on human behavior in architectural theory and practice ${ }^{12}$. Socially informed design rooted in evidence has entered the architectural discourse with the work of Jane Jacobs in US and Independent Group in UK, and later the international collaboration of Team $X$. Their polemics gained political momentum and eventually succeeded in overturning the then dominant paradigm of heroic masterplanning, propagated by top-down institutions like CIAM (Congrès Internationaux d'Architecture Moderne). In attempt to make these methods relevant and useful for the design process, architecture departments across the world started integrating sociologists, anthropologists and environmental psychologists. The result was the integration of social science into design curricula ${ }^{13}$ and an increased focus on social, integrative, responsive design. This direction led to the development of the scientific method as a basis for design - for an articulation of a rule, not an exception. Both the case studies, presented in schools and the competition entries were directed to understanding the unglamorous, vernacular, everyday.

Although integration of the social sciences in architecture was a natural progression of the rational, modernist thinking, it was not accepted univocally. There was a schism between the understanding of modernism as a process and the understanding of it as a style. This divergence was evident at the seminal exhibition at the MoMA curated by Philip Johnson and
Henry-Russell Hitchcock ${ }^{14}$. The newly identified 'International Style' betrayed the very basis of the modern movement, i.e. its social imperative. Becoming a 'style', high modernism became more obsessed with form and representation rather than with process and program. Continuing on the same tangent, the polemics of Jose L. Sert have interpreted sociological concerns to the ideas of 'New Monumentality.'

\section{THE SECOND CYCLE - POSTMODERN CRITIQUE}

Two decades into modernism's post-war and trans-Atlantic evolution brought to the next, postmodern revolt. Like the previous avant-garde, it created a double bind situation. Along with the rise of historicism and formalism in the work of architects such as Aldo Rossi, Charles Moore, and Michael Graves, there was a rise of pop-art and theories of the everyday. Both directions critiqued reductive functionalism, as well as the elitism of high modernism. While the first approach called for introspection, the latter advocated for further emancipation of the profession. Critics like Robert Venturi and Denise Scott-Brown, attacked the New Monumentality, identifying their works as 'ducks' (Venturi). They called for a more nuanced understanding of human needs, which would open up the discussion about 'function', moving away from "design for Man" towards "design for people:"

Modern architects reject the very heterogene-ity of our society that makes the social sciences relevant to the architecture in the first place... They build for man rather than for people - this means, to suit themselves, their own particular upper-middle class values, which they assign to everyone.

-Venturi and Rauch, Symbols in the American City, $1972^{15}$

Although Venturi and Scott-Brown were key figures in the postmodern movement, their call for in-depth learning of human behavior and vernacular cultures was suppressed by the overall critique of the modernist functionalism and synthetic 'social engineering'. This critique coincided with a growing disillusion with the promises of welfare state and architects starting to withdraw from the political arena, growing increasingly suspicious about any kind of social interventions. In this way, postmodernism has rejected engagement with the human subject altogether. Architectural discourse has seemingly left behind foundational work on human behavior in the built environment such as C.M. Deasy's 'Design for Human Affairs' and Robert Sommer's 'Tight Spaces', reducing studies of actual human behavior to cursory observations or desultory interviews.

Fredric Jameson traced this development, showing how the collapse of modernist grand narratives and the rise of postmodern architecture are aligned with the socioeconomic shifts of early neo-liberalism. The crises of the professions (Schön) in the late 1960s amidst the social and 
economic upheaval of those times brought about a period of introspection. This shift away from behavioral studies began in the late 1970s, as the architectural emphasis shifted from socially responsible and responsive design (Newman) to novelty and formal experimentation. ${ }^{16}$ Bernard Tschumi describes this evolution as follows:

[In] the mainstream of the prevalent archi-tectural discourse through the 1970s there was an exacerbation of stylistic concerns at the expense of programmatic ones and a reduction of architecture as a form of knowledge to architecture as a knowledge of form.

\section{-Bernard Tschumi, Architecture of Disjunction, $1996^{17}$}

This process was accelerated further through the early 1990s with the widespread mobilization and technical development of CAD and other digital design tools. With the possibility of developing ever-more virtual and outlandish shapes, the frontiers of the profession were directed away from mere prosaic functional requirements and programming concerns and toward three-dimensional swirls, swoops, and fractal loops. With the increased speed of both technical tool improvement and spread, the emphasis in education has shifted toward mastery of skill-sets for using these tools and away from examining the reasons for their use. ${ }^{18}$

Part of the postmodern inward-turning shift was a re-orientation of the discipline away from the empirical foundations of the work to a larger emphasis on phenomenology in both education and practice. A striving for disciplinary autonomy in the late $70 \mathrm{~s}^{19}$ drew the larger theoretical and philosophical discourses of that era (such as Lacan, Deleuze, and Derrida) towards a concentration on the inner world of the designer's mind. The most-studied cases are not of projects founded in the gathering of evidence or responding to specific social and cultural needs, but rather the exploration of wholly subjective impressions and expectations of personal feelings (Zumthor). Ultimately, the postmodern shift, with its emphasis on image, message, and text, reverted the power of parti and restored gesture and form to their thrones at the core of the field.

The emphasis on authorial power, of the ability of the designer to produce high art, has been a core component of studio education since the days of the Beaux-Arts, where parti became the metaphysics of design. Design exists as a projection of the genius mind, produced by the broadly-educated 'Renaissance Man', for the delight of the wealthy client and the social elevation of the patron. Deeply rooted in the traditional classification of architecture as the 'highest form of art' the celebrity mentality has been hard wired within the profession's psyche. Even the integration of technical rationality throughout the Industrial Revolution and the modernism has not disrupted the primacy of the author, as exemplified in such modern heroes as Frank
Lloyd Wright and Le Corbusier. Despite the constant attempts to dissolve 'starchitect' idolatry, which started with Gropius's teamwork (Giedion) and continued through the experiments in interdisciplinarity, the pertinence of elitist mentality remained.

\section{THE THIRD CYCLE - NEW MODERN OPTIMISM}

The technological and economical shifts of the 1990s, instigated by digitization and globalization has brought to the new turn of architectural discourse and signalled another cycle of social imperative. The new generation, championed by Dutch firms like OMA and MVRDV, challenged authorial power and formalist obsessions, while picking up Tschumi's earlier appeal to the primacy of programme. In 1995 Rem Koolhaas wrote:

The transition from a former position of power to a reduced station of relative humility is hard to perform. A profession persists in its fantasies, its ideology, its pretension, its illusions of involvement and control, and is therefore incapable of conceiving new modesties, partial interventions, strategic realignments, compromised positions that might influence, redirect, succeed in limited terms, regroup, begin from scratch even, but will never re-establish control.

-Rem Koolhaas, "Whatever Happened to Urbanism," $1995^{21}$

The ambivalent position regarding "control" was informed by the new socio-economic condition of global capitalism, when state powers subsided to privatized economic forces, dispersing and dissolving the centralized authority (Castells). The new condition challenged the role of the architect, who started to feel that they were "for decorative purposes only," as one architect put it. To regain positions, architects defined a new category of practice that they called "designing research" or "researching design." (Lootsma) ${ }^{20}$ The position of the researcher has enabled the architect to establish a critical distance between the author and the object of design (or critique), freeing the author from political and social responsibility and yet enabling free expression of critical opinion.

Similarly to 'paper architects' of the late 70s, these new designresearchers emerged from professional crisis in response to chaotic socio-economic environment. But unlike their predecessors, who concentrated on disciplinary autonomy, the new generation engaged in a dynamic dialogue with external fields of political theory, ecology, geography and computer science. Inspired by the emerging "sciences of complexity" and "big data" (Jencks), this new avant-garde produced new discursive terrains such as Datascapes (MVRDV), Field Conditions (Stan Allen) and Diagrammatic architecture (Van Berkel). This new outreach provided new tool-sets of databased social research, which opened up horizons for scientifically substantiated interdisciplinary exchange. 
However, despite the promising seeds for interdisciplinarity, the architectural ego and the societal tendency to idolship has prevailed again. The work of the former radicalists was engulfed and absorbed by the global capitalist crave for celebrity. And yet, their contribution was not in vain. The idea of distanced authorship was echoed by the growing initiatives on the ground in participatory design, placemaking movement and tactical urbanism. Springing from grassroots urban initiatives, this new outreach found a greater resonance within urban design rather than within architectural discipline.

Emerging from the outskirts of the mainstream theoretical discourse, this new wave of social imperative has strong foundations in earlier urban design studies, which were actively engaging observational methodologies of behavioral science. Protagonists of studying public life and 'everyday urbanism', such as Jan Gehl, William Whyte and Margaret Crawford, were shifting the focus yet again towards the ordinary practices of the everyday and away from object-centered formalist fixations. This work has redeemed the forgotten ideas of Venturi, Scott-Brown and their contemporaries, calling attention again to the people (in plural) and not to the Man (in platonic meaning of the word).

\section{CURRENT DEBATES AROUND ARCHITECTURE AND SCIENCE}

Contemporary discourse presents a schism between the pluralistic outreach culture and conservative inward-turning bias. The latter becomes ever stronger as the former gains momentum. It is demonstrated, for example, in the recent shift in National Architecture Accreditation Board language de-emphasizing the importance of human behavior in the built environment in favor of broader, less-defined, and more nebulous "human welfare." Such orthodoxy is deeply ingrained in defensive tradition of highly specialized intra-disciplinary codes protecting disciplinary boundaries - tradition that produces insular practitioners, relying on arcane codes and "archispeak" (Silber)22 to convey their subjective messages, incomprehensible to the wider public.

Suggesting the coexistence of a multitude of perspectives, a pluralism of postmodern and late modern discourses creates a phantom of the field's versatility. In reality the disarray of directions has only led to a greater disjunction. Each minidiscourse remains in its own segregated niche, increasing the overall secluded and self-referential nature of architectural discipline. Although leading contemporary theory and practice fosters intersections and cross-pollination with other disciplines, these experiments remain within isolated testtubes. In architectural education, external methods and modes of inquiry are either appended to studio courses as token readings, or relegated to elective courses at the periphery of the curriculum to satisfy university or accreditation standards.
Besides the ideological stance, the ambivalent relation- ship of architecture towards interdisciplinarity can be also observed in the methodological obscurity. Architecture does not have an established scientific methodology because it is not a science. Its set of rules is stretched in between art and engineering. Due to both its social foundations in distinction (Bourdieu) ${ }^{23}$ and cultural effects of suppression of innovation, aesthetics cannot be used as a baseline for meaningful critique. In addition to being a means to establish and maintain social power relations, the fluid and relative nature of aesthetic critique based in personal taste means that any aesthetic position can be viewed to be as valid as any other. Aesthetic distinction does not reside in the object of design itself, but in the perceptions of the creators and users of said design. Focusing on the design act, while being separated from its subject makes architecture self-referential and uncritical.

Poorly chosen case studies are the exemplar of this. If the case studies chosen to educate future professionals are of buildings chosen for their formal novelty, students will come to believe that such novelty is paradoxically the norm. Examining only the exceptional skews perceptions of practice. Students will eventually be strongly disappointed when their own practices are not filled with opportunities for formal exploration and expression. The exceptionalism of case studies, as indicated in the call, shows that architecture has lost interest in non-orthodox approaches to design and space. The fetishization of ever-more baroque forms belies the paucity of variety and cultural implications of these forms. Designs are considered innovative only inasmuch as their forms are. This feeds the educational emphasis on celebrity and the lionization of the avant-garde.

Further still, there is an inherent problem in the current trends to integrate other disciplines into the design process via "research by design." Design in and of itself is not a process of inquiry. It can explore, it can develop new forms, it can perhaps even discover more efficient or effective ways to design, but as long as research by design is based in design itself, founded on a kind of intensified introspection, it will limit its own potential and increase the insularity and isolation of the profession. In the contemporary optimistic moment of community outreach it is absolutely crucial to establish solid foundations for profound sociological research in order to avoid the catastrophic effects of unchecked social engineering and the appropriation of people's hopes towards the further nurturing of celebrity stance. Future work should focus on an engagement in true scientific discovery and unlearning self-referential designcentered methods by expanding the practice of humble and open dialogue. 


\section{ENDNOTES}

1. Esther Choi and Marrikka Trotter, Architecture at the Edge of Everything Else (Cambridge, MA: Work Books, 2010).

2. Quotes from the exhibition's website: "Now What?! Advocacy, Activism \& Alliances in American Architecture since 1968."

3. Quotes from the US pavilion website: "Dimensions of Citizenship, Venice Biennale."

4. Miranda Joseph, Against the Romance of Community, new edition (Minneapolis, MN: University of Minnesota Press, 2002); Gordon C.C. Douglas, The Help-Yourself City: Legitimacy and Inequality in DIY Urban- ism (Oxford, UK: Oxford University Press, 2018).

5. Robert Sommer, Social Design: Creating Buildings with People in Mind (Englewood Cliffs, NJ: Prentiss-Hall, 1983).

6. Rudolf Wittowker, Architectural Principles in the Age of Humanism (London: University of London Press, 1949).

7. Reyner Banham, The New Brutalism: Ethic or Aesthetic? (London: Architectural Primer, 1968).

8. Michael K Hays, Oppositions Reader: Selected Readings from Journal for Ideas and Criticism in Architecture 1973-1984 (New York: Princeton Arch. Press, 1998).

9. William J. R. Curtis, Modern Architecture Since 1900, 3rd edition (London: Phaidon, 1996).

10. Ernest Burgess, Robert Park, and Roderick D. McKenzie, The City (Chicago: The University of Chicago Press, 1925).

11. Edward W. Soja, Postmodern Geographies: The Reassertion of Space in Critical Social Theory (London: Verso, 1989).

12. Adrian Forty, Words and Buildings: A Vocabulary of Modern Architecture (London: Thames \& Hudson, 2004).

13. C.M. Deasy, Design for Human Affairs (Cambridge, MA: Schenkman, 1974)

14. "Modern Architecture: International Exhibition" exhibition curated by Philip Johnson and Henry-Russell. Hitchcock, Museum of Modern Art in New York, NY, 1932 The exhibition introduced an emerging architectural style known as the "International Style," it was described by Johnson as "probably the first fundamentally original and widely distributed style since the Gothic."

15. Venturi \& Rauch, Signs of Life: Symbols in the American City (New York: Aperture, Inc: 1972).

16. Fredric Jameson, Postmodernism, or, The Cultural Logic of Late Capitalism (Durham, NC: Duke University Press, 1992).

17. Bernard Tschumi, "Space and Events" in Architecture and Disjunction (Cambridge, MA: The MIT Press, 1996).

18. Boyer-Mitgang, The Boyer-Mitgang Report (Princeton, NJ: Carnegie Foundation, 1996).

19. K. Anthony, Design Juries on Trial: The Renaissance of the Design Studio, 20th anniversary edition, 2012 (New York: Von Nostrand Reinhold, 1991)

20. Bart Lootsma, "Reality Bytes," Diadolos 69/70 (1998/99): 8-21.

21. Rem Koolhaas, "Whatever Happened to Urbanism?" Design Quarterly 164 (Spring 1995): 28-31.

22. John Silber, Architecure of the Absurd: How "Genius" Desfigured a Practical Art (New York: Quantuck Lane, 2007)

23. Pierre Bourdieu, Distinction (London: Routledge Classics, 1986). 